\title{
Prognostic Impact of Absolute Lymphocyte Counts at the End of Remission Induction in Childhood Acute Lymphoblastic Leukemia
}

Jeffrey E. Rubnitz, MD, PhD ${ }^{1,2}$, Patrick Campbell, MD, PhD $^{1,2}$, Yinmei Zhou, MS ${ }^{3}$, John T. Sandlund, MD ${ }^{1,2}$, Sima Jeha, MD ${ }^{1,2}$, Raul C. Ribeiro, MD ${ }^{1,2}$, Hiroto Inaba, MD, PhD $^{1,2}$, Deepa Bhojwani, MD ${ }^{1,2}$, Mary V. Relling, PharmD ${ }^{2,4}$, Scott C. Howard, MD ${ }^{1,2}$, Dario Campana, MD, PhD $^{5}$, and Ching-Hon Pui, MD ${ }^{1,2,6}$

${ }^{1}$ Department of Oncology, St. Jude Children's Research Hospital, Memphis, Tennessee

${ }^{2}$ Department of Pediatrics, College of Medicine, University of Tennessee Health Science Center, Memphis, Tennessee

${ }^{3}$ Department of Biostatistics, St. Jude Children's Research Hospital, Memphis, Tennessee

${ }^{4}$ Department of Pharmaceutical Sciences, St. Jude Children's Research Hospital, Memphis, Tennessee

${ }^{5}$ Department of Paediatrics, National University of Singapore

${ }^{6}$ Department of Pathology, St. Jude Children's Research Hospital, Memphis, Tennessee

\section{Abstract}

Background-Absolute lymphocyte counts (ALC) during treatment have been associated with outcome in children and adults with hematologic malignancies. However, the impact of ALC relative to that of other prognostic factors on the outcome of children with acute lymphoblastic leukemia (ALL) treated in recent trials is unknown.

Methods-Outcomes of 399 patients $\leq 18$ years of age with newly diagnosed ALL who were enrolled in the Total Therapy XV study at St. Jude Children's Research Hospital were analyzed according to ALC at the end of remission induction therapy.

Results-ALC $\geq 500$ cell $/ \mu \mathrm{L}$ was significantly more prevalent among patients with B-lineage ALL, favorable presenting features and in those who achieved minimal residual disease (MRD) negativity on day 43 of treatment. Both overall survival (OS) and event-free survival (EFS) were superior among patients with higher ALC, but only the association with OS was statistically significant in a univariate analysis. In multivariable analyses, ALC was not a significant predictor of outcome after controlling for age, leukocyte count, lineage, risk group, and MRD at the end of induction ( $p>0.1$ for all comparisons). However, among MRD-negative patients, those with low ALC had a 5 -year OS of $84.2 \% \pm 8.9 \%$ versus $97.3 \pm 1.0$ for patients with higher ALC $(P=.036)$.

Conclusion-ALC at the end of induction is related to favorable presenting features and good initial treatment response but does not independently predict outcome in the context of contemporary, MRD-guided, therapy.

Corresponding author: Jeffrey E. Rubnitz, MD, PhD, Department of Oncology, St. Jude Children's Research Hospital, 262 Danny Thomas Place, Mail Stop 260, Memphis, TN 38105-2794; Phone: (901) 595-2388; Fax: (901) 521-9005; jeffrey.rubnitz@ stjude.org.

There are no conflicts of interest and no financial disclosures. 


\section{Keywords}

acute lymphoblastic leukemia; lymphocytes; pediatrics; prognosis

\section{INTRODUCTION}

In patients with acute leukemia undergoing hematopoietic cell stem transplantation (HSCT), absolute lymphocyte counts (ALC) post-transplant serve as an indicator of the speed and quality of engraftment and hematopoietic cell reconstitution and may also reflect the potential for graft-versus-leukemia activity. Thus, several studies have shown that higher ALC post-transplant predict a superior outcome in patients with either acute myeloid leukemia (AML) or acute lymphoblastic leukemia (ALL). ${ }^{1-9} \mathrm{~A}$ rapid regeneration of normal hematopoiesis after intensive chemotherapy should also be a favorable prognostic indicator, as this may reflect a deeper leukemia cytoreduction with a consequently higher functional capacity of the hematopoietic microenvironment. Conceivably, immune cells might also exert an anti-leukemic effect and suppress relapse. However, whether ALC have a prognostic impact in patients receiving chemotherapy alone is less clear. To this end, Behl et al. ${ }^{4}$ reported that ALC $\geq 500 / \mu \mathrm{L}$ after induction chemotherapy was associated with superior overall survival (OS) and event-free survival (EFS) in 103 patients with AML. Investigators of the Children's Oncology Group (COG) examined the effect of ALC in childhood leukemia. ${ }^{5,6}$ In an analysis of 171 patients $\leq 21$ years old, De Angulo et al. ${ }^{5}$ found that ALC during induction therapy was a significant predictor of survival in both ALL and AML. ${ }^{5}$ In a subsequent study of 171 pediatric ALL cases, Rabin et al. ${ }^{6}$ observed that ALC at day 29 of induction therapy was independently associated with relapse-free survival and OS. ${ }^{6}$

The level of minimal residual disease (MRD) during and after remission induction chemotherapy is the strongest prognostic factor in childhood ALL. ${ }^{10-13}$ MRD is an independent predictor of outcome and can define risk subgroups among clinically or genetically defined ALL subtypes. In the St Jude Total XV study for children and adolescents with newly diagnosed ALL, we incorporated MRD measurements in riskclassification algorithms and used them to guide therapy, a strategy that resulted in 5-year EFS and OS rates of $85.6 \%$ and $93.5 \%$, respectively. ${ }^{14}$ The study of Rabin et al. ${ }^{6}$ indicated that ALC after remission induction therapy predicted outcome even after adjusting for MRD status, suggesting that these were independent prognostic factors. To determine whether ALC held its prognostic significance in the context of MRD-directed therapy, we examined the impact of ALC on outcome in our Total XV cohort.

\section{PATIENTS AND METHODS}

\section{Patients}

From June 2000 to October 2007, 411 patients $\leq 18$ years of age with newly diagnosed ALL were enrolled in the Total Therapy XV study at St. Jude Children's Research Hospital. ${ }^{14}$ Treatment regimens, risk classification, and MRD methods have been previously described. ${ }^{14}$ ALC values were obtained at the time of remission evaluation, after six weeks of remission induction therapy. The study was approved by the institutional review board, and written informed consent or assent, as appropriate, was obtained for all patients

\section{Statistical Methods}

ALC values were analyzed separately as a categorical variable $(<500$ cells $/ \mu l$ vs. $\geq 500$ cells/ $\mu \mathrm{l}$ ) and as a continuous variable. Comparisons of ALC, treated as a categorical variable, between groups were performed by using the chi-square test. ALC treated as a continuous variable between groups was compared using the Wilcoxon rank-sum test when 
two groups were compared, and by the Kruskal-Wallis test when more than two groups were compared simultaneously. The duration of EFS was measured from the date of enrollment to the date of the first treatment failure of any kind (relapse, death, lineage switch, or second malignancy) or to the date of the most recent follow-up. Failure to induce remission was considered an event at time zero. The duration of OS was calculated from the date of enrollment to the date of death due to any cause or the date of the most recent follow-up. Data for patients who were alive at the most recent contact date were censored at the time of that contact. The Kaplan-Meier method ${ }^{15}$ was used to estimate the probability of OS and EFS, standard errors were determined by the method of Peto and Pike, ${ }^{16}$ and comparisons between groups were made using the log-rank test. The Cox proportional hazards regression model $^{17}$ was used to assess each potential prognostic factor in univariate and multivariable analyses, and hazard ratios were estimated with $95 \%$ confidence intervals.

All analyses were performed using SAS software (SAS Institute, Cary, NC), Windows version 9.2. All reported $P$ values are 2 -sided. The criterion for significance in all analyses was a probability of 0.05 or less $(P \leq .05)$, and no $P$-value adjustments were made for multiple comparisons.

\section{RESULTS}

\section{ALC at the end of remission induction therapy and relation with clinical features of ALL}

$\mathrm{ALC}$ at the end of remission induction ranged from 120 to 6942 cells/ $\mu 1$ (median, 1024 cells/ $\mu 1)$. Because ALC was associated with OS when cutpoints of 500 cells $/ \mu 1$ and 600 cells $/ \mu 1$ were used but was marginally associated with EFS only when a cutpoint of 500 cells/ $\mu$ l was chosen, we used 500 cells/ $\mu 1$ for subsequent analyses. As shown in Table 1, patients with ALC $\geq 500$ cells/ $\mu 1$ at the end of induction were more likely than patients with lower counts to have B-lineage ALL $(P<.001)$, have low-risk leukemia as defined by age and leukocyte count $(P=.001)$ and be MRD negative $(<.01 \%$ leukemic cells among bone marrow mononucleated cells) at the end of induction $(P=.005)$. When ALC was analyzed as a continuous variable (data not shown), higher counts were associated with age 1 to 9 years $(P$ $<0.001)$, B-lineage ALL $(P<.001)$, and low-risk features $(P<.001)$. Thus, higher ALC was characteristic of patients with favorable prognostic features and excellent initial treatment response.

Low ALC at the end of induction therapy may reflect a delayed recovery of bone marrow function. Thus, we compared the leukocyte, platelet, and absolute neutrophil counts between patients with ALC values above or below 500 cells/ $\mu 1$. Indeed, the median leukocyte count in patients with ALC $<500$ cells/ $\mu$ l was $1800 / \mu$ l (range, $400 / \mu l$ to $3900 / \mu \mathrm{l}$ ) as compared to $2900 / \mu \mathrm{l}$ (range, $500 / \mu \mathrm{l}$ to $33300 / \mu \mathrm{l})$ for patients with higher ALC $(P=.003)$; platelet counts were $135 \times 10^{3} / \mu 1\left(\right.$ range, $17 \times 10^{3} / \mu 1$ to $\left.344 \times 10^{3} / \mu 1\right)$ vs. $277 \times 10^{3} / \mu 1\left(\right.$ range, $23 \times 10^{3} / \mu 1$ to $\left.1220 \times 10^{3} / \mu \mathrm{l}\right)(P<.001)$.

\section{Relation between ALC and treatment outcome}

In a univariate analysis, ALC $\geq 500$ cells/ $\mu$ l was significantly associated with a superior OS: the 5-year OS estimate was $95.0 \% \pm 1.2 \%$ versus $82.4 \% \pm 6.8 \%$ for patients with ALC values lower than 500 cells/ $\mu \mathrm{l}(P=.023)$ (Fig. 1a); ALC was also significantly related to OS when analyzed as a continuous variable $(P=.029)$. Among other factors included in the analysis, age $(P<.001)$, MRD status $(P<.001)$, leukemic cell lineage $(P=.029)$, and initial risk group $(P=.001)$ were predictive of OS (Table 2$)$. Age $(P=.005)$, MRD status $(P<$. 001), leukemic cell lineage $(P=.002)$, initial risk group $(P<.001)$, and leukocyte count at diagnosis $(P=.040$ when analyzed as a continuous variable) were also significantly associated with EFS (Table 2). However, ALC was not significantly associated with EFS: 
the 5-year EFS estimates for patients with ALC values greater or lower than 500 cells $/ \mu \mathrm{l}$ were $88.0 \% \pm 1.8 \%$ vs. $76.5 \% \pm 7.6 \%$, respectively $(P=.053$; Fig. $1 \mathrm{~b})$; likewise, ALC lacked prognostic significance if analyzed as a continuous variable $(P=.092)$.

In a multivariable Cox proportional hazards regression model that included age, leukocyte count at diagnosis, leukemic cell lineage, initial risk group, and MRD at the end of induction, ALC, whether analyzed as a categorical $(P=.362$, Table 3$)$ or continuous $(P=$. 234 , data not shown) variable, was not associated with OS. We also performed a multivariable analysis that included ANC in the Cox model. However, the inclusion of ANC in the model did not change the results-ALC was not significantly associated with OS. Similarly, ALC was not significantly associated with EFS when analyzed as a categorical $(P$ $=.930$, Table 3$)$ or continuous $(P=.506$, data not shown $)$ variable. In the multivariable analyses, MRD remained significantly associated with OS and EFS $(P<.001)$; age was associated with OS $(P=.005)$ and initial risk group with EFS $(P=.003)$. To assess whether ALC may provide useful prognostic information in settings in which MRD measurement is not possible, the multivariable analyses were repeated without MRD in the model. In these analyses, ALC was not significantly associated with OS $(P=.176)$ or EFS $(P=.534)$.

Although the multivariable analyses showed no evidence that ALC was independently associated with outcome, we nevertheless performed subgroup analyses to determine whether ALC values might be prognostically useful for a subset of patients (Table 4). After adjusting for age, ALC was not significantly associated with OS or EFS in MRD-positive, low-risk, or standard/high-risk patients, but was associated with OS among MRD-negative patients (Fig. 2; Table 4). The 5-year estimates of OS were 97.3\% $\pm 1.0 \%$ for MRD-negative patients who had ALC values 2500 cells $/ \mu \mathrm{l}$ and $84.2 \% \pm 8.9 \%$ for patients with lower ALC $(P=.036$, Fig. 2). Three hematologic relapses occurred in the low ALC, MRD-negative group, including two patients with T-ALL and one patient with B-precursor ALL, all of whom had MRD levels greater than $1 \%$ at day 15 of remission induction therapy.

\section{DISCUSSION}

We assessed the prognostic impact of ALC at the end of remission induction in the context of contemporary MRD-directed therapy. We found that a higher ALC ( 2500 cell $/ \mu \mathrm{L})$ was significantly more prevalent among patients with B-lineage than T-lineage ALL, in those with favorable presenting features, and in those who had a good response to remission induction therapy and achieved MRD negativity on day 43. Patients with higher ALC at the end of induction also had higher leukocyte and platelet counts at the same time point. Both OS and EFS were superior among patients with higher ALC, but only the association with OS was statistically significant in a univariate analysis. ALC was not significantly associated with EFS or OS after adjusting for other risk factors, including age, leukocyte count, lineage, risk group, and MRD.

A recent COG study that showed that end-of-induction ALC is a significant predictor of outcome in children with ALL even after accounting for MRD. ${ }^{6}$ Several factors may explain the differences between the COG report and our findings. First, remission induction therapy on the COG trials consisted of 3 or 4 drugs given over a 4-week period, whereas the Total Therapy XV trial included 8 drugs in a 6-week induction period. Thus, ALC and MRD were evaluated at day 29 in the COG study and at approximately day 43 after more intensive therapy in our study. This difference in timing and intensity of therapy was reflected in higher ALC values in the COG study (median, 2280 cells/ $\mu 1$; range, 192-9890 cells/ $\mu \mathrm{l}$ ) than in our study (median, 1024 cells $/ \mu \mathrm{l}$; range, $120-6942$ cells $/ \mu \mathrm{l}$ ). The most important difference, however, was the outcome for MRD-positive patients in the two studies. In the COG report, relapse-free survival and OS rates for patients with low ALC and positive 
MRD were $33 \%$ and $41 \%$ respectively, compared with EFS and OS rates of $69 \%$ and $77 \%$ for the corresponding group in our study. In the COG study, ALC identified MRD-positive patients with dismal or very good OS rates (41\% vs. $92 \%$ for those with low or high ALC, respectively), whereas ALC was not associated with survival among MRD-positive patients in our study (77\% vs. $84 \%)$.

Our results suggest that the modification of therapy based on MRD, pharmacogenetics, and pharmacodynamics, along with careful supportive care, can abrogate the prognostic effect of both traditional and novel factors. Although age was associated with OS and risk group was predictive of EFS, MRD was the only factor that was independently associated with both OS and EFS. By contrast, multivariable analysis showed that leukemic cell lineage, leukocyte count, and ALC were not independently associated with OS or EFS. This suggests that any negative effect potentially associated with low ALC, particularly among MRD-positive patients, was overcome by intensification of chemotherapy. Of note, MRD-negative patients with ALC values $<500$ cells $/ \mu l$ in our study had a significantly worse outcome than those with higher counts within this group, a finding that requires further investigation.

It has been proposed that the favorable impact of higher ALC after chemotherapy or HSCT for hematologic malignancies reflects enhanced immunologic effects of autologous or allogeneic lymphocytes. ${ }^{2,6,8,9}$ Anti-leukemic effects have been ascribed to T-cell subsets ${ }^{18,19}$ and NK cells. ${ }^{2,9}$ It is clear that among patients undergoing HSCT, allogeneic NK cells play a key role, as donor NK cells may exert potent antileukemic effects when the patient's leukemia cells lack the class I epitope for the donor's inhibitory killer immunoglobulin-like receptors. ${ }^{20-22}$ In addition, the normalization of NK cell receptor expression may be prognostically important in patients receiving chemotherapy. A study of adult AML patients revealed that the acquisition of an NK cell-triggering receptor (NCR)dull phenotype was reversible in patients who achieved remission. ${ }^{23}$ An association between the NCR-dull phenotype and poor survival in these patients suggests that recovery of normal NCRs may allow the recovery of normal NK cell function, which, in turn, contributes to sustained remission. While this and other studies suggest an important role for immune surveillance after chemotherapy, $2,5,6$ the results of the present study indicate that intensive chemotherapy may compensate for the lack of such immune effects.

\section{Acknowledgments}

This work was supported in part by Cancer Center Support (CORE) grant P30 CA021765-30 from the National Institutes of Health and by the American Lebanese Syrian Associated Charities (ALSAC). Ching-Hon Pui is an American Cancer Society Professor.

The authors thank David Galloway, ELS, for expert editorial review, Tad McKeon for data collection, and Julie Groff for preparing the figures.

\section{References}

1. Porrata LF, Litzow MR, Tefferi A, et al. Early lymphocyte recovery is a predictive factor for prolonged survival after autologous hematopoietic stem cell transplantation for acute myelogenous leukemia. Leukemia. 2002; 16:1311-1318. [PubMed: 12094255]

2. Lowdell MW, Craston R, Samuel D, et al. Evidence that continued remission in patients treated for acute leukaemia is dependent upon autologous natural killer cells. Br J Haematol. 2002; 117:821827. [PubMed: 12060116]

3. Kumar S, Chen MG, Gastineau DA, et al. Lymphocyte recovery after allogeneic bone marrow transplantation predicts risk of relapse in acute lymphoblastic leukemia. Leukemia. 2003; 17:18651870. [PubMed: 12970788] 
4. Behl D, Porrata LF, Markovic SN, et al. Absolute lymphocyte count recovery after induction chemotherapy predicts superior survival in acute myelogenous leukemia. Leukemia. 2006; 20:2934. [PubMed: 16281063]

5. De AG, Yuen C, Palla SL, Anderson PM, Zweidler-McKay PA. Absolute lymphocyte count is a novel prognostic indicator in ALL and AML: implications for risk stratification and future studies. Cancer. 2008; 112:407-415. [PubMed: 18058809]

6. Rabin KR, Gramatges MM, Borowitz MJ, et al. Absolute lymphocyte counts refine minimal residual disease-based risk stratification in childhood acute lymphoblastic leukemia. Pediatr Blood Cancer. 2012; 59:468-474. [PubMed: 22102553]

7. Le BK, Barrett AJ, Schaffer M, et al. Lymphocyte recovery is a major determinant of outcome after matched unrelated myeloablative transplantation for myelogenous malignancies. Biol Blood Marrow Transplant. 2009; 15:1108-1115. [PubMed: 19660724]

8. Savani BN, Mielke S, Rezvani K, et al. Absolute lymphocyte count on day 30 is a surrogate for robust hematopoietic recovery and strongly predicts outcome after T cell-depleted allogeneic stem cell transplantation. Biol Blood Marrow Transplant. 2007; 13:1216-1223. [PubMed: 17889359]

9. Savani BN, Mielke S, Adams S, et al. Rapid natural killer cell recovery determines outcome after Tcell-depleted HLA-identical stem cell transplantation in patients with myeloid leukemias but not with acute lymphoblastic leukemia. Leukemia. 2007; 21:2145-2152. [PubMed: 17673900]

10. Campana D. Status of minimal residual disease testing in childhood haematological malignancies. Br J Haematol. 2008; 143:481-489. [PubMed: 18710378]

11. Coustan-Smith E, Behm FG, Sanchez J, et al. Immunological detection of minimal residual disease in children with acute lymphoblastic leukaemia. Lancet. 1998; 351:550-554. [PubMed: 9492773]

12. Coustan-Smith E, Sancho J, Hancock ML, et al. Clinical importance of minimal residual disease in childhood acute lymphoblastic leukemia. Blood. 2000; 96:2691-2696. [PubMed: 11023499]

13. Conter V, Bartram CR, Valsecchi MG, et al. Molecular response to treatment redefines all prognostic factors in children and adolescents with B-cell precursor acute lymphoblastic leukemia: results in 3184 patients of the AIEOP-BFM ALL 2000 study. Blood. 2010; 115:3206-3214. [PubMed: 20154213]

14. Pui CH, Campana D, Pei D, et al. Treating childhood acute lymphoblastic leukemia without cranial irradiation. N Engl J Med. 2009; 360:2730-2741. [PubMed: 19553647]

15. Kaplan EL, Meier P. Non-parametric estimation for incomplete observations. J Am Stat Assoc. 1958; 53:457-481.

16. Peto R, Pike MC, Armitage $\mathrm{P}$, et al. Design and analysis of randomized clinical trials requiring prolonged observation of each patient. II. analysis and examples. Br J Cancer. 1977; 35:1-39. [PubMed: 831755]

17. Cox DR. Regression models and life-tables. J R Stat Soc Series B Stat Methodol. 1972; 34:187220.

18. Szczepanski MJ, Szajnik M, Czystowska M, et al. Increased frequency and suppression by regulatory $\mathrm{T}$ cells in patients with acute myelogenous leukemia. Clin Cancer Res. 2009; 15:33253332. [PubMed: 19417016]

19. Kanakry CG, Hess AD, Gocke CD, et al. Early lymphocyte recovery after intensive timed sequential chemotherapy for acute myelogenous leukemia: peripheral oligoclonal expansion of regulatory T cells. Blood. 2011; 117:608-617. [PubMed: 20935254]

20. Leung W, Iyengar R, Triplett B, et al. Comparison of killer Ig-like receptor genotyping and phenotyping for selection of allogeneic blood stem cell donors. J Immunol. 2005; 174:6540-6545. [PubMed: 15879158]

21. Hsu KC, Keever-Taylor CA, Wilton A, et al. Improved outcome in HLA-identical sibling hematopoietic stem-cell transplantation for acute myelogenous leukemia predicted by KIR and HLA genotypes. Blood. 2005; 105:4878-4884. [PubMed: 15731175]

22. Leung W, Iyengar R, Turner V, et al. Determinants of antileukemia effects of allogeneic NK cells. J Immunol. 2004; 172:644-650. [PubMed: 14688377]

23. Fauriat C, Just-Landi S, Mallet F, et al. Deficient expression of NCR in NK cells from acute myeloid leukemia: Evolution during leukemia treatment and impact of leukemia cells in NCRdull phenotype induction. Blood. 2007; 109:323-330. [PubMed: 16940427] 

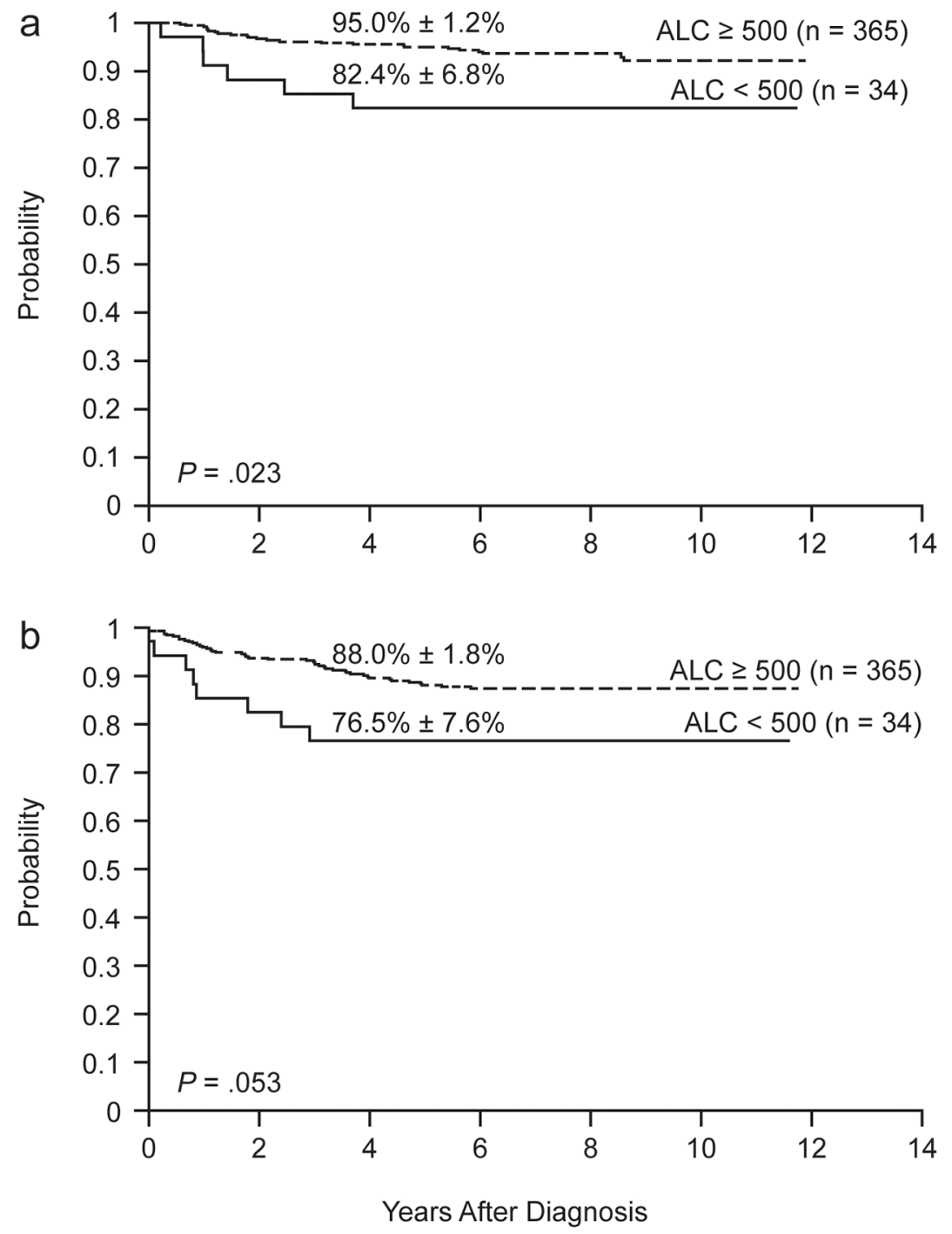

Figure 1.

Overall survival (a) and event-free survival (b) according to ALC at the end of remission induction therapy. 

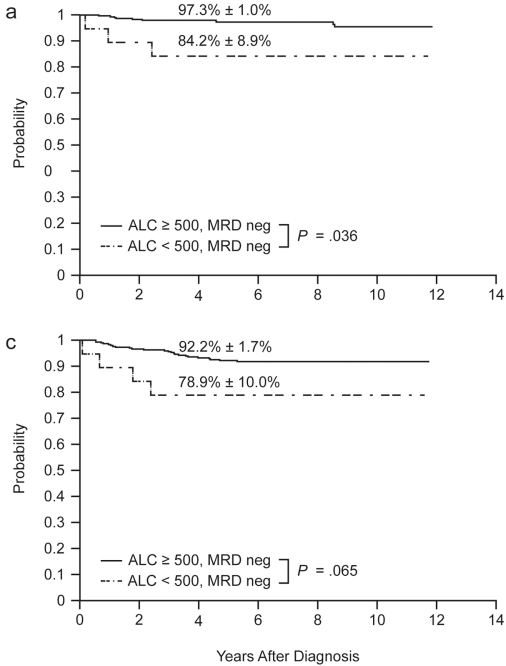
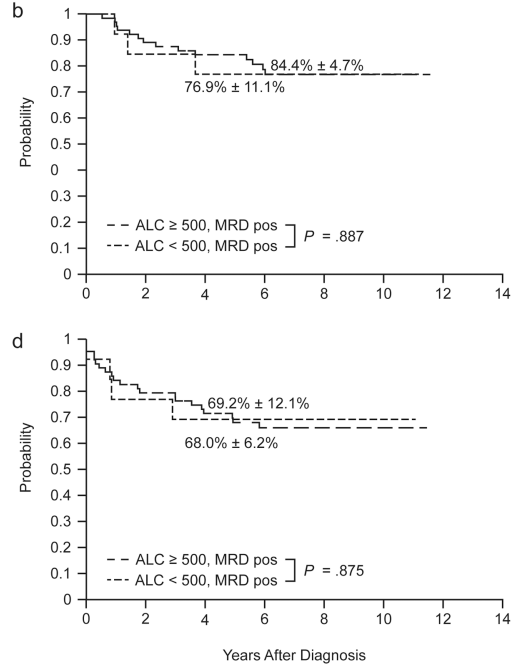

Figure 2.

Overall survival (a, b) and event-free survival (c, d) according to ALC at the end of remission induction therapy and minimal residual disease (MRD) status (neg, negative; pos, positive). 
Table 1

Absolute lymphocyte count distribution

\begin{tabular}{|c|c|c|c|c|}
\hline Variable & Total $(n=399)$ & ALC $<500$ cells $/ \mu \mathrm{l}(\mathrm{n}=34)$ & ALC $\geq 500$ cells $/ \mu \mathrm{l}(\mathrm{n}=\mathbf{3 6 5})$ & $P$-value ${ }^{*}$ \\
\hline \multicolumn{5}{|l|}{ Age at Diagnosis (\%) } \\
\hline 1 to 9 years & 293 & $21(7.2)$ & $272(92.8)$ & .107 \\
\hline$\geq 10$ years & 106 & $13(12.3)$ & $93(87.7)$ & \\
\hline \multicolumn{5}{|l|}{ Leukocyte count (\%) } \\
\hline$<50 \times 10^{3} / \mu \mathrm{L}$ & 293 & $25(8.5)$ & $268(91.5)$ & .989 \\
\hline $250 \times 10^{3} / \mu \mathrm{L}$ & 106 & $9(8.5)$ & 97 (91.5) & \\
\hline \multicolumn{5}{|l|}{$\operatorname{MRD}(\%)$} \\
\hline Negative $(<0.01 \%)$ & 318 & $19(6.0)$ & $299(94.0)$ & .005 \\
\hline Positive ( $\geq 0.01 \%)$ & 77 & $13(16.9)$ & $64(83.1)$ & \\
\hline Missing & 4 & $2(50.0)$ & $2(50.0)$ & \\
\hline \multicolumn{5}{|l|}{ Lineage $(\%)$} \\
\hline B & 336 & $19(5.7)$ & $317(94.3)$ & $<.001$ \\
\hline $\mathrm{T}$ & 63 & $15(23.8)$ & $48(76.2)$ & \\
\hline \multicolumn{5}{|l|}{ Initial risk group (\%) } \\
\hline Low & 223 & $10(4.5)$ & $213(95.5)$ & .001 \\
\hline Standard/High & 176 & $24(13.6)$ & $152(86.4)$ & \\
\hline
\end{tabular}

ALC, absolute lymphocyte count; MRD, minimal residual disease

* Pearson's chi-square test 


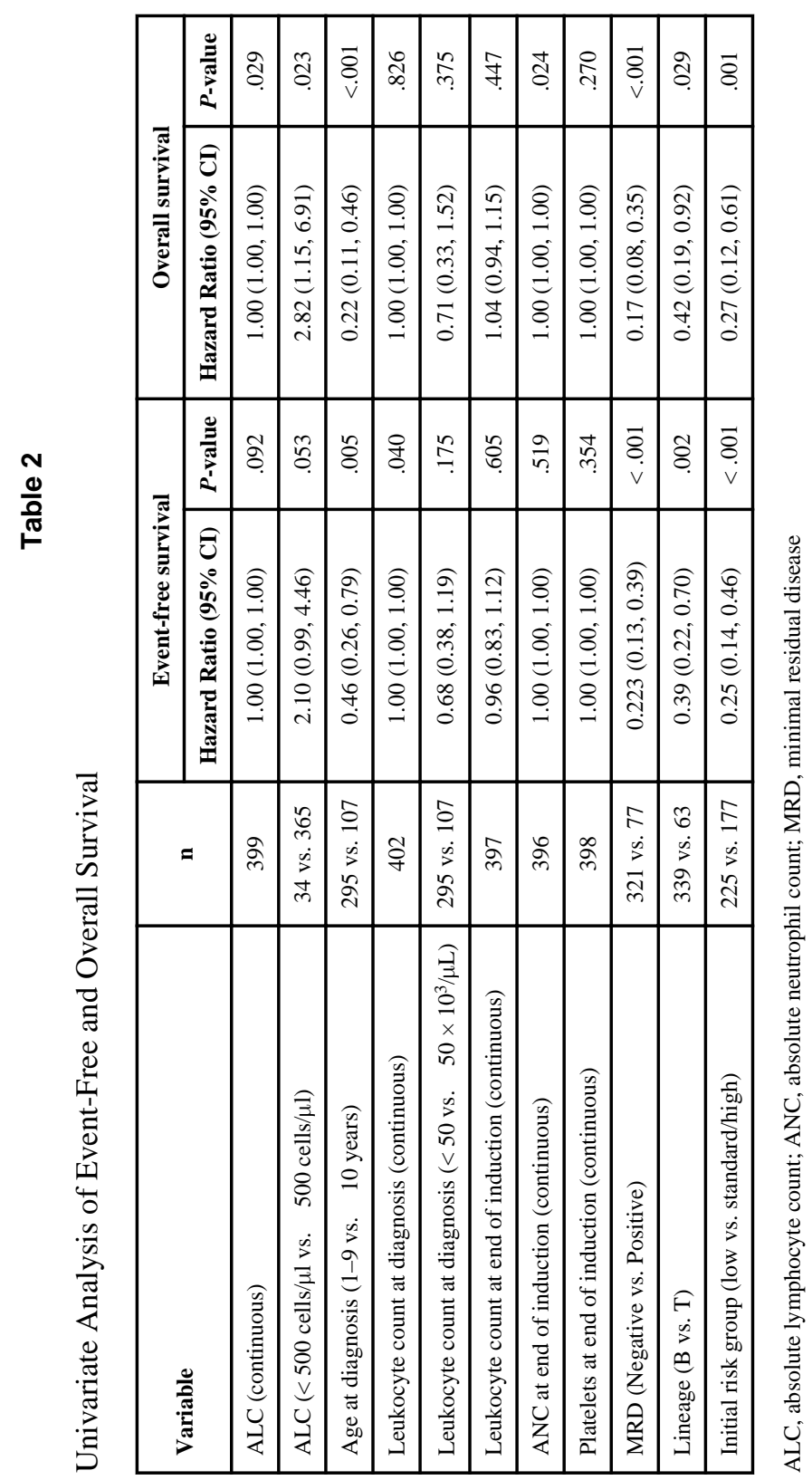

Cancer. Author manuscript; available in PMC 2014 June 01. 
Table 3

Multivariable Cox Proportional Regression Model (ALC as a categorical variable)

\begin{tabular}{|l|c|c|c|c|}
\hline \multirow{2}{*}{ Variable } & \multicolumn{2}{|c|}{ Event-free survival } & \multicolumn{2}{c|}{ Overall survival } \\
\cline { 2 - 5 } & Hazard Ratio $(\mathbf{9 5 \%}$ CI) & $\boldsymbol{P}$-value & Hazard Ratio (95\% CI) & $P$-value \\
\hline ALC $(<500$ cells/ $\mu 1$ vs. $\geq 500$ cells/ $\mu$ l) & $1.04(.44,2.42)$ & .930 & $1.62(.57,4.56)$ & .362 \\
\hline Age at diagnosis $(1$ to 9 vs. $\geq 10$ years) & $.90(.49,1.66)$ & .736 & $.30(.13, .70)$ & .005 \\
\hline Leukocyte count at diagnosis $\left(<50\right.$ vs. $\left.\geq 50 \times 10^{3} / \mu \mathrm{L}\right)$ & $1.39(.71,2.70)$ & .334 & $1.00(.41,2.50)$ & .996 \\
\hline Lineage $($ B vs. T) & $.80(.39,1.65)$ & .548 & $.90(.33,2.45)$ & .836 \\
\hline Initial risk group (low vs. standard/high) & $.30(.14, .66)$ & .003 & $.70(.24,2.01)$ & .505 \\
\hline MRD (Negative vs. Positive) & $.30(.17, .53)$ & $<.001$ & $.22(.10, .46)$ & $<.001$ \\
\hline
\end{tabular}

ALC, absolute lymphocyte count; MRD, minimal residual disease 


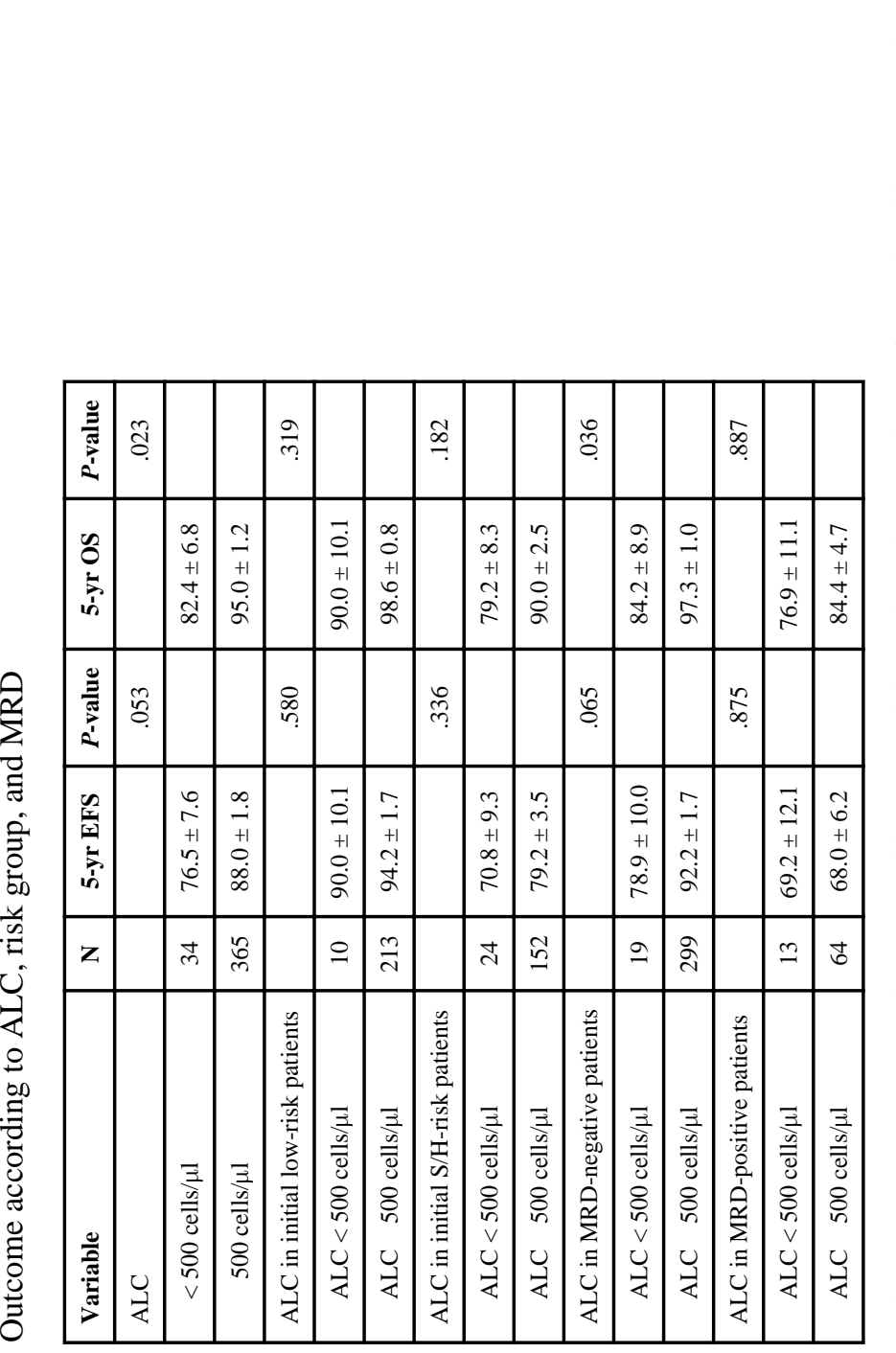

